Gress, S., Groenewegen, P., Kerssens, J., Braun, B., Wasem, J.

Free choice of sickness funds in regulated competition: evidence from Germany and the Netherlands.

Health Policy: 60, 2002, nr. 3, p. 235-254

Postprint Version 1.0

Journal website $\quad$ http://dx.doi.org

Pubmed link http://www.ncbi.nlm.nih.gov/entrez/query.fcgi?cmd=Retrieve\&db=pubmed\&dop $\underline{\mathrm{t}=\text { Abstract\&list uids }=11965333 \text { \&query } \mathrm{hl}=57 \text { \&itool=pubmed docsum }}$

DOI 10.1016/S0168-8510(01)00193-2

Abbreviations: AOK, Allgemeine Ortskrankenkassen (basic or regional sickness funds); BKK, Betriebskrankenkassen (company sickness funds); CVZ, College voor Zorgverzekeringen (council for health insurance); EAN, Ersatzkrankenkassen für Angestellte (substitute funds for white-collar workers); EAR, Ersatzkrankenkassen für Arbeiter (substitute funds for blue-collar workers); GEK, Gmünder Ersatzkasse (individual sickness fund); GKV, Gesetzliche Krankenversicherung (statutory health insurance); IKK, Innungskrankenkassen (guild sickness funds); SOEP, Sozioökonomisches panel (socioeconomic panel).

* Corresponding author. Tel.: +49-3834-86-2456; fax: +49-3834-86-2475. E-mail address: gress@unigreifswald.de (S. Greß).

\title{
Free choice of sickness funds in regulated competition: evidence from Germany and The Netherlands
}

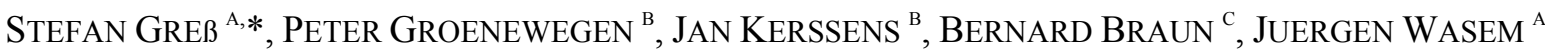 \\ a Ernst-Moritz-Arndt-University Greifswald, Institute for Health Care Management, Friedrich-Loeffler- \\ Str. 70, D-17489 Greifswald, Germany \\ b Netherlands Institute for Health Services Research (NIVEL), P.O. Box 1568, 3500 BN Utrecht, The \\ Netherlands \\ c ZeS, Centre for Social Policy Research, University of Bremen, Parkallee 39, 28209 Bremen, \\ Germany
}

\begin{abstract}
Sickness funds became the focal point of health insurance reforms in the 1990s. Policy makers expected funds to become more consumer-oriented and more active in managing the provision of health care. This is especially true for two countries in the heart of Europe that, on first view, have many similar institutional characteristics. Both Germany and The Netherlands have introduced competition between sickness funds in the last decade. We present extensive quantitative, as well qualitative, data with regard to the behaviour of consumers after the introduction of free choice between sickness funds. National data was used with regard to contribution rates and member flows and survey data was used to investigate personal motives for actual change and perception of differences between sickness funds. In Germany, contribution rates between sickness funds differ significantly. Accordingly, these differences are the main reason for consumers to switch funds, which occurs on a considerable scale. However, survey data show that other reasons may be important too. In The Netherlands, premium differences are much lower. The same is true for the degree of change. Survey data show that consumers perceive very small differences between sickness funds and do not see much reason for change. Our findings support the claim that the degree of actual changing depends strongly on economic incentives, especially with regard to the extent of financial risk sickness funds have to bear and to the extent premiums or contribution rates can
\end{abstract}


Gress, S., Groenewegen, P., Kerssens, J., Braun, B., Wasem, J.

Free choice of sickness funds in regulated competition: evidence from Germany and the Netherlands.

Health Policy: 60, 2002, nr. 3, p. 235-254

differ. However, the higher the financial risk of individual sickness funds actually is, the higher the incentives for risk selection.

\section{INTRODUCTION}

Sickness funds are the focal point of health system reforms in social insurancebased health care systems. Giving the insured the free choice between sickness funds is supposed to bring about competition that would, at the same time, favor quality through selective contracting by sickness funds and curb the costs through incentives for efficiency. ${ }^{1}$ In this article, we analyze the role of freedom of choice of sickness funds in health reforms and we present data about the extent of actual choices made by the insured.

The decade from approximately 1985 to 1995 can be characterized as the decade of health reforms. In this period, numerous Western European countries launched larger or smaller health reforms $[2,3]$. It is also the decade that witnessed the fall of communism and the start of the economic and social transition of the former communist systems of Central and Eastern Europe. Generalizing over all European countries, the trend in the reforms was away from government planning to some system of regulated competition and from a supply-oriented health care system to a demand-oriented system $[4,5]$.

A closer look at reforms and reform attempts shows the differences between health care systems in their approach towards reform. Still, at a rather general level, health reforms are different for the National Health Service systems of Western Europe, for the social insurance systems and for the transitional countries. Although the reforms aim at the same general improvements, the structure and history of groups of countries determine the specific directions chosen. The transitional countries are in a particular situation because the current system is more or less revolutionalized. The reforms in most of the transitional countries are directed towards a social insurance system, privatization and decentralization [6].

The national health systems in Western Europe have in common that health care is funded from taxation, either regionally or nationally, that tax money is allocated, according to some rule, to health authorities who provide health care to the population of their region, that health services are in kind and that most of the health personnel are salaried employees. In these systems, important elements in health reforms are to create an internal market by splitting up the purchase and the provision of care and to give people a wider range of choice between health facilities by letting the money follow the patient and not the other way around [7].

The social insurance systems are funded by income dependent premiums and are administrated by sickness funds, which have contractual relations with independent providers, facilities and services in kind or restitution. In these systems, the focus of the reforms is the insurance system and, more specifically, the sickness funds, by introducing freedom of choice of a sickness fund for the insured and some formula to allocate the insurance premiums to the sickness funds [8].

For competition between sickness funds to get started and to work, people must have some choice between sickness funds. In Hirschman's terminology: 'the insured must have the exit option' $[9,10]$. However, people need information regarding differences between sickness funds in order to realize their exit option. Finally, in order that sickness funds focus on quality and efficiency of health care services, it is also necessary to arrange that the sickness funds will not compete by risk selection. Therefore, it is necessary that the formula to allocate the premium money to the sickness funds or the systems of pooling the risks ensure that it does not pay to try to select the better risks [11].

In this article, we compare data from two social insurance based health care systems, Germany and The Netherlands. In Germany and The Netherlands, reform attempts have been made and the sickness funds were focal points in these reforms. In both countries, it was made possible for insured people to change sickness funds. Firstly, we will try to answer the question whether people do indeed change sickness funds in these countries, how many change, what their motives are and why perhaps people do not change. Secondly, we will try to draw conclusions from this comparison about the role of free choice in enhancing competition between sickness funds.

\footnotetext{
${ }^{1}$ Due to specific attributes of the market for health care services and for health insurance, this competition is usually regulated quite extensively [1]
} 
Gress, S., Groenewegen, P., Kerssens, J., Braun, B., Wasem, J.

Free choice of sickness funds in regulated competition: evidence from Germany and the Netherlands.

Health Policy: 60, 2002, nr. 3, p. 235-254

\section{DESCRIPTION OF THE SICKNESS FUND SYSTEMS OF THE NETHERLANDS AND GERMANY}

The role sickness funds play in a system of regulated competition depends on the specific rules in the different countries. This background information is collected in Table 1. It briefly describes the membership rules, part of the population that is insured, the service package, the premiums, the financial responsibility of the funds and the objects of competition.

\section{[ TABLE 1 ]}

Reform attempts that use the position of sickness funds as their point of departure have focused on three points. The first is the relation between the insured people and their sickness funds. Traditionally in The Netherlands, people had no free choice of sickness funds at all and in Germany, only insured groups had some limited choice. Funds membership depended on their job or the place of living. In the 1990s, choice was made possible in The Netherlands (in 1992) and was extended in Germany to virtually all insured (in 1996). In Germany, the sickness funds already had different premiums, but in The Netherlands, this incentive for choice had to be introduced in the form of a flat-rate part of the premium (apart from the uniform income dependent part). It was and is expected that differences in premiums induce people to choose the cheaper insurance with the best service and that sickness funds are induced to increase their efficiency and service orientation in order to lower their costs and increase their attractiveness to the insured.

In The Netherlands also, a second relation was changed, that between the sickness funds and the health care providers. Initially, the sickness funds were forced to contract with every provider in their area and in Germany, with some (so far minor) exceptions, they still are. Both countries have services in kind; hence, there must be a stable relation between sickness funds and providers. Abandoning obligatory contracting was an important change in The Netherlands because it gave way to the possibility of selective contracting, based on quality and costs of the services provided. In practice, however, selective contracting has not developed yet [12].

A third drive for sickness funds to work efficiently is the extent to which they are actually responsible for their financial results. In The Netherlands, sickness funds were not responsible at all for their financial results. If sickness funds had higher costs than what they received as premiums, the difference was added by a central fund. In Germany, the same was true for a large group of their insured, the old age pensioners. Financial responsibility has been introduced stepwise in The Netherlands and is now at a point that sickness funds are responsible for $38 \%$ of their deficits; in Germany, financial responsibility was extended to $100 \%$ in 1995 .

All in all, a number of rules have changed, most in The Netherlands, less in Germany. The incentives for sickness funds to compete with one another differ between the countries. The instruments of competition also differ. In The Netherlands, competition is focused on three areas: the fixed part of the premiums, collective contracts with companies to insure all employees (irrespective of whether they are sickness fund eligible or privately insured) and probably, to a lesser extent, the supplementary insurance. In Germany, the competition is based on the income dependent premiums and to a lesser extent, some services for which sickness funds themselves can decide whether to include them in the package (such as alternative medicine). To a rather limited extent, sickness funds use their contracts with providers to differentiate from each other.

The rules for changing sickness funds are more or less the same in The Netherlands and Germany: people can change once a year and have to notify their sickness fund before a fixed date. They are also free to change upon a change of premiums. In Germany, insured people can also switch their sickness funds when changing employers, which is not possible in The Netherlands.

\section{QUANTITATIVE EFFECTS OF THE INTRODUCTION OF FREEDOM OF CHOICE}

Although the two health insurance systems examined agree on the main principles of introducing free choice for consumers, their differences in monitoring processes and gathering national relevant information do not allow a direct comparison from a common data base. However, by using national data it is possible to get a valid impression with regard to three important parameters. First, it is important to obtain information about the monetary incentives for consumers to change. Second, we 
Gress, S., Groenewegen, P., Kerssens, J., Braun, B., Wasem, J.

Free choice of sickness funds in regulated competition: evidence from Germany and the Netherlands.

Health Policy: 60, 2002, nr. 3, p. 235-254

have gathered information on the development of premium differences and the flow of sickness fund members. Finally, we try to establish the degree of correlation between premium differences and member flow for each of the countries.

\subsection{Germany}

The German government introduced freedom of choice between sickness funds in two steps in 1996 and 1997. Before the introduction of freedom of choice for all insured, only white-collar workers were legally able to change. Blue-collar workers were restricted to only a small number of funds. In order to understand the complicated market structure of German sickness funds, it is important to understand the roots of this market structure in history. For that reason, we have included a short prefix on the history of German 'Krankenkassen'.

\subsubsection{History of German sickness funds}

The first Health Insurance Act in Germany was implemented in 1883. Several types of sickness funds were instituted by law in order to become carriers of social health insurance. The law accepted both a whole range of already existing funds and demanded new funds to be established. Even before the Health Insurance Act, there were several voluntary sickness funds, mostly founded by unions, local authorities and guilds. According to the law, new funds could be founded by companies and regional authorities. Interestingly enough, there was strong competition between the sickness funds. Sickness funds did offer several choices with regard to the size of the benefits package and the way benefits were paid for (benefits-inkind versus benefits-in-cash). In a German journal, Abel-Smith [13] dubbed this early stage of German health insurance as a model for US-Health Maintenance Organizations: "If we look at the 19th century we can see that in many European countries the former voluntary health insurers behaved just in the same way as the so-called Health Maintenance Organizations - they look for the best value for money and are not afraid to establish competition between providers", (translation by the authors). ${ }^{2}$

More or less intentionally, legally there was a development towards a hierarchical system of access to sickness funds. In general, all insured had access to the regional or basic funds (Allgemeine Ortskrankenkassen or AOK). If there was a sickness fund founded by the company or the guild the insured were working for, these insured had to enter the company fund (Betriebskrankenkassen or BKK) or the guild fund (Innungskrankenkassen or IKK). Finally, there were so-called substitute funds for white-collar workers (Ersatzkassen für Angestellte or EAN) as well as blue-collar workers (Ersatzkassen für Arbeiter or EAR). ${ }^{3}$ These substitute funds had limited access for status groups of employees. This structure cannot be understood in any functional terms, but has its roots in development since the Health Insurance Act in 1883. Step by step, competition on the market for health insurance was reduced by law. However, there was still competition for sub-groups of the insured that led to a risk-segmentation of the market. Especially company funds, guild funds and some prestigious substitute funds had a much better-thanaverage risk structure which resulted in low contribution rates. The basic funds had a worse-than-average risk structure because they had a higher share of social security recipients, unemployed and elderly persons that resulted in higher contribution rates. The implementation of free choice between sickness funds and a risk adjustment mechanism following the Health Reform Act of 1992 is supposed to lead to equal choice for all insured and to a more homogenous risk structure of the sickness funds. It is important to note that this reform did not introduce selective contracting of providers, while at the same time the level of services remained standardized. Only after the implementation of the reforms, were concepts such as managed competition or socially-bounded competition discussed [15].

\subsubsection{Contribution rate differences}

Sickness funds determine their contribution rate individually. After the introduction of risk adjustment (two steps in 1994 and 1995) and of free choice for consumers (two steps in 1996 and

2 Even with limited competition between sickness funds, competition de facto has always existed in the German health care sector. This includes competition among private health insurers, between private health insurers and social health insurance funds for insured above the income ceiling and between physicians [14].

3 These funds were named substitute funds because membership in these funds was a substitute for membership in AOK, BKK or IKK. 
1997), contribution rate differences dropped significantly. Contribution rate differences between the funds with the highest contribution rate and the funds with the lowest contribution rate in the former West Germany dropped from 2\% in 1993 to $1 \%$ in $1999 .{ }^{4}$ While $27 \%$ of all members paid a contribution rate differing by more than $1 \%$ point from the average in 1994, this number has dropped to $7 \%$ in 1999 [16]. ${ }^{5}$ However, lately differences started to increase again to $1.4 \%$ points in 2001 [17]. Company funds (BKK) on average still have the lowest contribution rate, while local funds (AOK) on average have lost their position as most expensive funds to the substitute funds for salaried employees (EAN) that are now also open to blue-collar workers.

While average contribution rate differences between groups of funds have declined, there are still significant differences between individual funds. Accordingly, in some regions consumers are able to choose between a contribution rate of $11.2 \%$ and a contribution rate of almost $15 \%$. What does this mean in terms of absolute figures? By switching from the most expensive to the cheapest insurer, consumers can save 18.5 Euro per month per 1000 Euro gross income. Even by switching to an insurer with a higher contribution rate, such as $12.5 \%$, a consumer with a gross income of 3000 Euro can save as much as 36 Euro per month or 432 per year plus the same amount of savings for the employer. Even insured with a small or medium income can save a significant amount of money. Incentives to change grow proportionally with income if we assume that the costs of gathering information and of the administrative procedure of switching are the same for all income groups. ${ }^{6}$

\subsubsection{Member losses and member gains}

While contribution rate differences between sickness fund groups decline, there are still significant price incentives for insured to switch to individual funds offering approximately the same benefits for less money. Accordingly, we should expect a significant number of insured to change. From December 1995 (last month of restricted right to choose) to January 2001 (last month with available data) the AOK have lost 2.7 million members or $12 \%$, while the BKK have won 3.2 million members or $61 \%$. The EAN have lost 0.6 million members or 3.2\%. The EAR have won 34,000 members or $3.7 \%$, the IKK have also won 0.2 million members or 7\% [17]. Estimates for the share of insured changing each year range from 3 to $5 \%[18]^{7}$

\subsubsection{Correlation between contribution rate differences and member losses/gains}

Information about the development of contribution rate differences and the development of market shares allows us to calculate the correlation between these two parameters. Fig. 1 correlates the member losses/gains in terms of absolute member changes to contribution rate differences. There is a very strong negative correlation in the West $(r=-0.99)$. Correlation in the East is somewhat weaker $(r=-0.82)$.

\section{[ FIGURE 1 ]}

Unfortunately, we do not have access to information about the development of both parameters for all individual sickness funds. However, we are able to confirm the conclusion drawn from aggregated data with some micro-data. We have calculated the same parameters for all individual AOK (West). This group is quite heterogeneous, although not as much as the company funds. The result of our calculation is in line with the findings so far. Individual AOK funds with the highest contribution rates also have the highest member losses, while individual AOK funds with lower contribution rates have the lowest member losses $(r=-0.87)$.

4 It is important to note that these data are aggregated and depict the average of individual funds belonging to one type of funds. There are large premium differences within these groups. Due to an ongoing concentration process, it is extremely difficult to analyse the development for individual sickness funds.

5 In the former East Germany, the development was not as significant since contributions did not differ as much as in the former West Germany.

6 Income levels vary between groups of sickness funds. The average income of non-pensioners in BKK funds is_30\% higher than in AOK funds.

7 Unfortunately, this figure is not part of the official statistics. 
Gress, S., Groenewegen, P., Kerssens, J., Braun, B., Wasem, J.

Free choice of sickness funds in regulated competition: evidence from Germany and the Netherlands.

Health Policy: 60, 2002, nr. 3, p. 235-254

We conclude that there is a very clear correlation between price and switching behavior. In Section 4.1, we analyze the characteristics and motives of sickness funds changers in Germany to validate this relationship.

\subsection{The Netherlands}

The effects of free choice in the Dutch health insurance system are examined by using the same parameters as in the last section. However, there is one important distinction. While for German consumers the individual contribution rate of sickness funds is important, in The Netherlands only the flat rate premium is subject to fluctuations between sickness funds. But first, a short history of Dutch sickness funds is included in a prefix.

\subsubsection{History of Dutch sickness funds}

Although the first Health Insurance Act in The Netherlands was implemented in 1941 under German occupation in World War II, the origin of the first sickness fund dates back to 1847, when progressive physicians and local authorities established the 'Algemeen Ziekenfonds Amsterdam'. This fund was managed by representatives of both physicians and insured and aimed at low income laborers [19]. But even then, there was already a long history of guild-funds for laborers and private insurance funds for the well-to-do. The following period of industrialization brought about a growing number of sickness funds from different confessional and social backgrounds and the turn of the 19th century witnessed more than 500 of them [20]. They were competing, not only by different benefit packages and premiums, but also by risk selection.

In 1912, the first attempted act to regulate the market was frustrated by the representatives of physicians who opposed the obligatory access and management solely by insured [21]. Thirteen years later, the unions formulated a compromise in their Unification report, but for a long period, the problem was left unfinished. In 1941, not surprisingly, the occupying forces introduced the German model of health insurance, with obligatory membership, uniform benefit packages, uniform income dependent premiums, executed by sickness funds with a regional monopoly under a supervising commissioner. Differences between sickness funds almost completely disappeared [21].

After 1945, this health insurance act was maintained, replacing the supervising commissioner by a supervising committee with representatives of physicians, hospitals, sickness funds, insured, employees and employers' associations, and government appointed members (according to the now fashionable Dutch term 'poldermodel'). In 1965, a new health insurance act with only minor changes was adopted. In the late 1980s, the Dutch government asked a commission, headed by the former Phillips board member Dekker, for suggestions to improve the Dutch health care system. Both government and commission felt that public regulation did not work effectively in the past, that the fragmented system of finance lead to inefficiency and that actors did not have enough incentives [22].

\subsubsection{Premium differences}

In the early years of free choice between sickness funds between 1992 and 1995 the flat rate premium was constant at 198 NGL $(\approx 90$ Euro) and with only one exception at 192 NLG ( $\approx 87$ Euro), all sickness funds charged the same premium. In 1996, this began to change, since all flat rate premiums increased and differences between sickness funds became larger. At the same time, health insurers had to face increased financial risk. During 1997 and 1998, the premiums decreased a little on average, but differences between sickness funds increased. One sickness fund chose a rather large decrease of its flat rate premium in these years. In 1999, the premium increased again and so did the differences between the sickness funds. These findings again are in line with the increase of financial risk. The S.D. increased from almost zero to 27.8 and premium differences between the funds with the highest premium and the funds with the lowest premium increased from $3 \%$ in 1995 to $28 \%$ in 1999 .

Thus, relative price differences between insurers increased quite significantly. However, in absolute terms, potential savings for the individually insured are rather low. Individuals who switch from the most expensive insurer to the cheapest insurer can save $<4$ Euro per month or 44 Euro per year. Furthermore, potential benefits in supplementary insurance are not included which may also be relevant for the decision to change [23].

\subsubsection{Member losses and member gains}


Gress, S., Groenewegen, P., Kerssens, J., Braun, B., Wasem, J.

Free choice of sickness funds in regulated competition: evidence from Germany and the Netherlands.

Health Policy: 60, 2002, nr. 3, p. 235-254

Since premium differences between sickness funds expanded, the insured can profit by switching to other funds offering the same benefits for less money. One behavioral assumption behind the Dutch reform was that an increasing number of insured would decide to change. From 1995 to 1999, only one sickness fund gained a considerable amount of members - almost 100,000 since 1995. Four others gained $>20,000$. Three sickness funds experienced a relatively large loss of $>20,000$ members. The majority of funds gained only a little. In total, gains are larger than losses, indicating a growing market. Between 1995 and 1999, the total number of insured increased from 9.7 to 9.9 million.

\subsubsection{Correlation between premium differences and member losses/gains}

Information about the development of premium differences and the development of market shares allows us to calculate the correlation between these two parameters. Fig. 2 depicts the member losses/gains and premium differences for 24 individual sickness funds between 1995 and 1999.

\section{[ FIGURE 2 ]}

As can be observed, high flat rate premiums do not necessarily correlate with member losses. On the other hand, low flat rate premiums seem to coincide with member gains. There is only a small linear correlation $(r=-0.21)$ between those two parameters which is not significant statistically.

These findings contrast strongly with the evidence from Germany, since correlation between premium differences and switching behavior is much lower. By comparing the maximum amount of money insured in The Netherlands and in Germany are able to save by switching, the reasons for this contrast should be obvious. They are confirmed by survey data on the reasons of insured to change or not to change in the next section.

\section{EVIDENCE ON MOTIVES TO CHANGE SICKNESS FUNDS}

In the last section, we have seen that there is strong empirical evidence, at least in Germany, that premium differences and member losses/gains are correlated. For The Netherlands, results are more ambiguous. In this section, we present survey data from several sources. We focus on the perceptions of differences between sickness funds and motives for actual change (or non-change). ${ }^{8}$

\subsection{Germany}

There has been a lack of continuous reporting on the reasons and motives for changing one's statutory health insurance fund. Thus, there is no basis for longitudinal analyses. Instead, several qualitatively varying insights into the current situation exist only for different points in time.

To date, solely the annually conducted Socioeconomic Panel (SOEP) provides representative data. In the SOEP, information on the number and socio-demographic characteristics of people who change their health insurance fund and the type of health insurance fund they change from and to is collected. A second source of data is provided by the analyses on people who change their health insurance fund that have been conducted or commissioned by various sickness funds. Funds conducted these kinds of surveys at various times since the introduction of the free choice of sickness funds for consumers. These are usually very differentiated studies, but in most cases are not available for public and scientific discussion. Sickness funds usually state that they do not want to provide additional information for their competitors. An additional useful source in this context is a survey of all persons who left or chose an individual sickness fund, Gmuender Ersatzkasse (GEK). ${ }^{9}$ The survey was conducted at the end of 1996 and at the beginning of 1997, i.e. at the first opportunity for free choice of sickness funds.

According to the SOEP results, the most important reason for changing one's sickness fund was a lower contribution rate (59\% of respondents). The importance of this reason varied with the type of sickness fund that was left or chosen. Low contribution amounts, for example, are the primary reason

8 Unfortunately, there is no published survey data on the perception of differences between sickness funds in Germany.

9 The GEK had_1.3 million insured, about half were old age pensioners and non-wage-earning family members in the whole country at that time. For historical reasons, male skilled workers from industry are over-represented in the GEK. The study of people changing from or to the GEK was conducted by the Centre for Social Policy of the University of Bremen by means of mailed surveys at the beginning of 1997. 
Gress, S., Groenewegen, P., Kerssens, J., Braun, B., Wasem, J.

Free choice of sickness funds in regulated competition: evidence from Germany and the Netherlands.

Health Policy: 60, 2002, nr. 3, p. 235-254

for $65.3 \%$ of those leaving the AOK. This is only surpassed by the $85.3 \%$ figure for the ex-members of an EAN sickness fund. By contrast, the contribution rate represents a reason for changing the health insurance scheme for only $7.8 \%$ of all former BKK members [24]. This result provides a mirror of the actual differences in contribution rates (as indicated in Section 3.1.2) between the types of health insurance funds within the framework of statutory health insurance in Germany.

Other reasons were better benefits (23\%), better service (16\%), image (17\%) and miscellaneous reasons $(20 \%)$. The most important miscellaneous reasons mentioned in the survey are unemployment and especially a change of employer or branch of industry. This was particularly high among former BKK and IKK members. This is probably due to the law that made it possible for these two types of health insurance funds to restrict choice. For example, each of the $\approx 400$ independent company health insurance schemes (BKK) and guild health insurance funds (IKK) can decide in their by-laws to remain 'closed', i.e. not having to or not being allowed to admit members from outside the specific company or trade.

Further routine socio-demographic characteristics of the SOEP clarify the social background of the insured and their decisions to change. If we compare the characteristics of changers and non-changers, we find younger, unmarried men with Abitur (university entrance qualification) and polytechnic/university degree more frequently among the changers. Moreover, this group of persons makes less use of outpatient physicians and claims to have better health than those who do not change their health insurance scheme.

Although it cannot be finally ascertained to what extent certain judgements with regard to social policy and basic attitudes are related to changing one's sickness fund, in this category changers differ significantly from non-changers. So considerably fewer changers tend to have the attitude that the government is responsible for taking care of social security 'for everyone' and many of them feel, by contrast, that everyone has to assume responsibility for this 'on his/her own'.

Now we discuss the results of the survey among people entering and leaving the GEK. Since this survey was conducted for a specific health insurance company, it is not representative of the whole population. However, several of the results of the SOEP regarding the reasons for changing sickness funds are confirmed. Furthermore, it supplies more differentiated and in-depth information on social policy attitudes, expectations and motives than the SOEP.

One group with diffuse motives, consisting of $3 \%$ of the persons surveyed, who wanted 'to try out something new' and another comprising nearly $10 \%$, who felt 'they were no longer in good hands', contrasted with $80 \%$ who had specific reasons for changing their health insurance scheme [25]. Of these specific reasons, the contribution rate rates highest. Some $91 \%$ of respondents $(N=11,078)$ considered this reason very important or important for their decision to switch. Next rank services offered by the GEK (75\%), the image of the GEK (64\%) and insufficient personal attention at the former health insurer $(25 \%)$. Other reasons are the rejection of applications for benefits at the former insurer $(18 \%)$, poor information at the former insurer $(15 \%)$ and poor accessibility of the former insurer with regard to time $(13 \%)$ and location $(9 \%)$.

Interestingly enough, the spectrum of reasons for changing health funds differs only gradually when the persons who left the GEK during the same period were questioned. Exactly two-thirds of these persons stated the lower contribution rate of the new health insurance fund as reason for change, while $46 \%$ mentioned additionally or exclusively the services offered. Between 13 and $18 \%$ stated organizational reasons or circumstances involving the granting of benefits as the reason for changing.

On first view, a surprising revelation is the high degree of satisfaction of changers with the sickness fund that they had left a few weeks prior to the survey: only $9.5 \%$ of the members who left the GEK were 'dissatisfied' or 'less satisfied' with it. By contrast, 32.1\% said that they were 'completely satisfied' with it and $23.7 \%$ stated they were 'very satisfied'. However, this finding is quite well in line with the overall importance of contribution rates. If there are no large differences between sickness funds in service quality or benefits, the decision to change is much easier. There is only one parameter left and that is the contribution rate.

Even when the reasons for changing health insurance scheme were specific, i.e. they were based on significant negative experiences in some cases, this led to neither a condemnation of the old sickness fund nor to euphoric praise for the new one. For example, those new members of the GEK who stated they had already had practical experience with their new health insurance company felt that they were better off than before only as far as the contribution amount was concerned. With regard to other 
perceptible aspects, such as the specialized competence of the staff, the extent of benefits or the time for processing applications, a majority or a strong minority of changers assessed their old health insurance company as being at least 'equally good'. In terms of proximity and accessibility, the new health insurance company was even felt to be worse by $40 \%$ of the changers.

\subsection{The Netherlands}

Data was obtained from the Dutch Health Care Consumers Panel, a panel resulting from a random sample of Dutch households and representative (among other things) for age, gender and type of health insurance. All households were selected with at least one member of a sickness fund $(N=1100)$. A mailed survey was completed by 846 out of 1100 (response 77\%) participants in early spring 2000 .

Table 2 shows that the insured perceive the differences between sickness funds as being quite small. The added result of the two answer categories 'very large differences' and 'large differences' is not bigger than $30 \%$ for any item. The highest percentage is for the extent of the supplementary coverage package and its premium (both 30\%). Only 19\% perceive large or very large differences of the flat rate premium. This perception is in line with our findings in Section 3.2.2. Some 14\% perceive large or very large differences between the basic benefits packages of individual sickness funds although the basic benefits package is uniform.

\section{[ TABLE 2 ]}

In the past 5 years, 200 persons (23.6\% of 846) have been thinking about changing from one sickness fund to another. Only a minority ( 76 or $9 \%$ of 846 ) tried to change and still a smaller number actually did change ( 56 or $6.6 \%$ of 846 ). Twenty persons called off their change, for instance, because it involved too much red tape, the cancellation time had expired or the new sickness fund turned out to be not cheaper after all. Of the 200 persons who thought of changing, seven persons did not provide any reason. Reasons for changing sickness funds vary a lot. Some 59 respondents (30\%) stated the limited coverage of supplementary insurance as a reason while 49 respondents $(25 \%)$ were not satisfied with service and communication. A total of 38 respondents $(20 \%)$ thought that the premium for supplementary coverage was to high, while 36 respondents (19\%) considered the flat rate premium to be too high. Less than 20 respondents, respectively thought that bill were not remunerated quickly enough, changed jobs and stated that their insurer has a bad name. Less than ten respondents thought of switching because they moved to another region, did not remember or because of recommendation by their physician. Additionally, we asked all persons for an answer to the question 'I do not benefit much from changing sickness fund'. A majority of $62 \%$ (totally) agreed with this statement, $29 \%$ were neutral and only $9 \%$ did not agree [26].

Further, we examined associations between the intention to change and several personal characteristics of the respondents in a multiple logistic regression analysis.

Respondents were divided into two categories: persons who did not think of changing $(N=646)$ and persons who have been thinking of changing or actually did change $(N=200)$. Personal characteristics were: age, sex, education, employment status, income, marital status, size of family and subjective health. Two characteristics showed a significant association. Older persons had a smaller probability to change than younger persons (Odds ratio $=0.97$ ) and higher educated persons had a larger probability to change than less educated people $(\mathrm{OR}=1.25)$.

\section{DISCUSSION}

In this article, we have examined the effects of price competition between sickness funds and the introduction of free choice for consumers in two rather similar health insurance systems. We found that in Germany, comparatively many people changed within only a few years and that many sickness funds have won or lost a significant number of insured. The level of the contribution rate is strongly correlated with wins and losses of members. This finding is supported by surveys asking people about the reasons for changing sickness funds. ${ }^{10}$ The vast majority of persons who changed their sickness

\footnotetext{
${ }^{10}$ Only for the initial phase of the free choice of sickness funds is there meaningful data for Germany. Because of the fact that the framework for such decisions has not changed dramatically (price differences between types of funds and especially individual funds are still quite high), we assume that the current spectrum of reasons has not altered either.
} 
Gress, S., Groenewegen, P., Kerssens, J., Braun, B., Wasem, J.

Free choice of sickness funds in regulated competition: evidence from Germany and the Netherlands.

Health Policy: 60, 2002, nr. 3, p. 235-254

fund had specific reasons for doing so. At the top of the list is clearly the contribution rate. However, a low contribution rate is seldom the only reason. Additional specific experience with the type, extent and quality of services of the health insurance company also plays a role as a supplementary or even as the only reason. Therefore, a significant proportion of the persons changing sickness funds takes advantage of the opportunity of free choice of sickness funds to sanction non-monetary and/or carerelated deficits of their old sickness fund.

Even when there are specific reasons for change, those who change do not seem to be profoundly affected by the stated service gaps or image deficits that they were neither induced to make a completely negative assessment of the old health insurance company nor to make an enthusiastic positive assessment of their new sickness fund. Whether this finding is sufficient for sickness funds to be able to win these insured back through specific changes cannot be demonstrated. However, the nonexistence of simple black-and-white assessments is an important prerequisite for being able to consider this aspect in the first place.

A look at the specific differences in socio-demographic background or social policy attitudes of changers and non-changers shows that there are more complex motives for changing one's health insurance scheme or remaining in it than only the contribution rate and certain service qualities. For example, persons with greater economic resources and better health status tend to change more often. Since especially people with lower health status tend to stay with their sickness fund and some funds have a risk structure which is significantly worse than the risk structure of the average fund, a welldeveloped risk adjustment mechanism is of utmost importance.

Much less happened in The Netherlands. Differences between the flat rate premium of individual sickness funds are low and so are member wins and losses of individual sickness funds. Accordingly, correlation between both parameters is very weak. Since we do not know much about why people prefer one health insurer above another, we investigated their reasons and checked the importance of the supplementary benefit package and the flat rate premium. The most frequently mentioned reason for being enlisted with a particular insurer is because a person has joined one in early adulthood. Neither the flat rate premium nor the supplementary premium seems to be very relevant. The supplementary benefit package is more important. Only a minority of persons thought of changing from social health insurer in the past 5 years and very few people did change.

Furthermore, people do not perceive many differences between benefit packages of various health insurers and think that the amount of red tape involved is not worth the possible benefits of a change. Competition between sickness funds can best be aimed at young people who enter the market. Once a sickness fund is chosen, not many people change. In the private health care sector, companies are competing via low premiums for students, reflecting the same market strategy that at the same time selects the better educated.

We consider the increased degree of choice in the German system as beneficial, since now all insured are free to choose almost every fund. Before, this option was restricted to white-collar workers only. In The Netherlands, the beneficial effect of free choice is less clear, since most insured do not perceive large differences between individual funds. However, sickness funds seem to increase administrative efficiency and to provide better service for their customers. Our findings support the claim that the degree of actual changing depends strongly on economic incentives, especially premiums or contribution rates. The high intensity of price competition in Germany is probably also due to the fact that while in Germany at least groups of insured were able to choose before the implementation of choice for all insured after 1995, in The Netherlands choice between sickness funds has been impossible until 1992. In the first years after 1995, choice in Germany was not only a matter of realizing savings due to a lower contribution rate, but also a matter of gaining social status for bluecollar workers. Nowadays, this reason for change has become less important.

Premium differences or contribution rate differences only occur if sickness funds are at financial risk. The higher the financial risk of individual sickness funds actually is, the higher are incentives for risk selection. This is true for The Netherlands as well as for Germany. A well working risk adjustment is an important prerequisite for price competition. Even before the introduction of free choice in Germany, risk adjustment has decreased the differences of contribution rates significantly. However, at the moment price competition on the German health insurance market is highly distorted, since differences in the contribution rates still do not reflect differences in administrative and productive efficiency of individual sickness funds but diverging risk structures. Without a more advanced risk- 
adjustment mechanism, these distortions gravely endanger the stability of the system. In The Netherlands, the smaller the degree of financial risk, the smaller the potential for price competition and the more extensive risk adjustment mechanism prevent risk selection quite effectively.

We have seen that the increase of choice, or in Hirschman's terms, the increase of exit, can have substantial benefits. Exit can induce sickness funds to increase the quality of administrative services for their insured. In both countries, this effect is obvious. However, exit so far did not increase the quality of health services because either the funds lack instruments to do so (Germany) or do not use available instruments such as selective contracting (Netherlands). Of course, even in The Netherlands the limited degree of financial risk and the restriction of selective contracting to individual providers, such as general practitioners or specialists, decreases the scope of instruments and incentives for insurers to improve quality of services.

If positive effects are limited to administrative services and more equity in choice, the costs of exit also have to be considered. There are extensive costs of regulation and implementation for government and substantial transaction costs for market actors. Additionally, the costs of weakening the voice option have to be considered. In Germany, employers and employees used to have a strong position in self-governing bodies of sickness funds. Their position is weakened if market development determine the strategic behaviour of individual funds. Unfortunately, the effectiveness of these self-governing bodies at the time of introduction of free choice was quite low. However, a strong exit option probably means that an enhancement of that effectiveness is not on the agenda of policy makers.

It is probably too early to make up the balance of this part of the health care reforms of the social insurance based systems of The Netherlands and Germany. Institutional changes, such as these, might take some time and a number of adjustments before they work well. However, until now the problems seem rather big, especially in Germany where preferred risk selection poses a large problem for the stability of the system. At the moment, there seems to be a trade-off between a high degree of price competition with rather big differences in contribution rates based on risk selection (Germany) and a rather low degree of price competition with rather small differences in contribution rates based on much lower financial risk and more effective risk adjustment (Netherlands). Policy makers in Germany quite urgently have to address the question of how to stabilize the German system and maintain freedom of choice at the same time, while policy makers in The Netherlands face the task of how to make choice for consumers more attractive without destabilizing the system. Our findings definitely support the claim that the degree of actual change depends strongly on the degree of differences in contribution rates or premiums.

\section{ACKNOWLEDGEMENTS}

The Dutch part of the research was funded by a research grant from VGZ-zorgverzekeraars to NIVEL. The German part of the research was largely funded by a research grant from the HansBöckler-Foundation to the Centre for Social Policy Research. Furthermore, we thank two anonymous referees for their valuable comments.

\section{REFERENCES}

[1] Enthoven A. The history and principles of managed competition. Health Affairs 1993;12:S24-48.

[2] OECD. The reform of health care: a comprehensive analysis of seven OECD countries. Paris: OECD, 1992.

[3] OECD. The reform of health care systems: a review of seventeen OECD countries. Paris: OECD, 1994.

[4] Saltman R, von Otter C, editors. Implementing Planned Markets in Health Care. Buckingham: Open University Press, 1995.

[5] Saltman R, Figueras J. European Health Care Reform: Analysis of Current Strategies. Copenhagen: World Health Organization, 1997.

[6] Marrée JTC, Groenewegen P. Back to Bismarck: Eastern European Health Care Systems in Transition. Aldershot: Avebury, 1997.

[7] Bartlett W, Roberts JA, Le Grand J. The development of quasi-markets in the 1990s. In: Bartlett W, Roberts JA, Le Grand J, editors. A Revolution in Social Policy: Quasi-Market Reforms in the 1990s. Bristol: The Policy Press, 1998. 
Gress, S., Groenewegen, P., Kerssens, J., Braun, B., Wasem, J.

Free choice of sickness funds in regulated competition: evidence from Germany and the Netherlands.

Health Policy: 60, 2002, nr. 3, p. 235-254

[8] van de Ven W, van Vliet R. How can we prevent cream skimming in a competitive health insurance market? The great challenge for the 90s. In: Zweifel P, Frech HE, editors. Health Economics Worldwide. Dordrecht: Kluwer, 1992:23-46.

[9] Hirschmann A. Exit, Voice and Loyalty-Responses to Decline in Firms, Organizations and States. Cambridge: Harvard University Press, 1970.

[10] Schlesinger M. Choice, managed care and managed competition: interactions and extrapolations. Department of Epidemiology and Public Health, Yale University, 1995. (Unpublished manuscript) [11] Schut FT, van Doorslaer EKA. Towards a reinforced agency role of health insurers in Belgium and the Netherlands. Health Policy 1999;48(1):47-67.

[12] Groenewegen P, Greß S. Die Auswirkungen der wettbewerbsorientierten Reformen im niederländischen Gesundheitswesen auf die Beziehungen zwischen Hausärzten, Krankenkassen und Versicherten. Das Gesundheitswesen 2000;62(11):568-76.

[13] Abel-Smith B. Alter Wein in neuen Schläuchen-Die Reform des Gesundheitswesen in länderübergreifender Betrachtung. DOK 1995;13:427-30.

[14] Pfaff M, Wassener D. Reconsidering the role of competition in health care markets: Germany. Journal of Health Politics Policy and Law 2000;25(5):907-14.

[15] Henke K-D. Socially bounded competition in Germany. Health Affairs 1999;18(4):203-6.

[16] European Observatory on Health Care Systems. Health Care Systems in Transition-Germany. Copenhagen: European Observatory on Health Care Systems, 2000.

[17] Ministry of Health. GKV-Statistik. Bonn: Ministry of Health, 2001.

[18] Müller J, Schneider W. Entwicklung der Mitgliederzahlen, Beitragssätze, Versichertenstrukturen und RSA-Transfers in den Zeiten des Kassenwettbewerbs-empirische Befunde im dritten Jahr der Kassenwahlrechte. Arbeit und Sozialpolitik 1999;3-4:21-39.

[19] van der Hoeven HC, van der Hoeven EW. Om Welzijn of Winst-100 jaar ziekenfondsen en sociale zekerheid. Den Haag: AZIVO, 1993.

[20] Blaauwbroek H, Hoeven E, Visser E. In Het Belang Van de Verzekerde-Geschiedenis Van de Ziekenfondsraad. Zeist: Stichting Historie Ziekenfondswezen, 1997.

[21] van der Hoeven HC. Ziekenfondsen en de Duitse Bezetting. Den Haag: Koninklijke Vemande BV, 1989.

[22] Ministry of Welfare Health and Cultural Affairs. Changing health care in the Netherlands. Rijswijk: Ministry of Welfare Health and Cultural Affairs, 1988.

[23] Schut F. Prijsconcurrentie ziekenfondsen nog niet effectief. Economisch Statistische Berichten 2001;86:172-5.

[24] Andersen H, Schwarze J. GKV '97-kommt Bewegung in die Landschaft?-Eine empirische Analyse der Kassenwahlentscheidungen, Veröffentlichungsreihe des Berliner Zentrums Public Health. Public Health 1998;2.

[25] Braun B. Ergebnisse einer Befragung von Ein- und Auswechslern der Gmünder Ersatzkasse. Bremen/Schwäbisch Gmünd: Manuscript, 1998.

[26] Kerssens J, Delnoij D, Verweij J, van der Schee E. De Keuze van Ziekenfondsverzekerden voor een Zorgverzekeraar. Utrecht: NIVEL, 2000. 
Table 1

Health insurance systems in The Netherlands and Germany, 2001

\footnotetext{
${ }^{a}$ In 1999 , the accumulated level of financial reserves of all sickness funds was $\approx 430$ million Euro.

Obligatory for employees under the income ceiling of $\approx 40,000$ Euro (2001) and their families, old age pensioners and some groups of self-employed, such as farmers. Voluntary membership possible.

$90 \%(8 \%$ private insurance, $2 \%$ others or uninsured)

Medical care, pharmaceutical prescriptions, care, dental care $<18$ years. Supplementary, voluntary hospital care, dental care, sick pay. insurance possible (e.g. for dental care $>18$ years and Supplementary voluntary insurance not parts of physiotherapy).

possible with the sickness funds, but only with private insurance.

Income dependent part is uniform, paid by employees and employers to the central fund, distributed to the individual funds. Prospective risk adjustment

Income dependent premium, determined by the sickness funds, paid by employees and employers. Retrospective risk adjustment according to capitation formula based on age, gender, based on age, gender, family size and income. region and employment status. Flat-rate part of premium determined by the individual sickness funds.

Financial responsibility of the sickness funds share of expenses, currently $38 \%$. Minimum level of financial reserves $(\approx 500,000 \text { Euro per fund })^{\text {a }}$

Flat-rate part of the premiums, supplementary insurance, collective insurance contracts with large firms.

$100 \%$ individual responsibility of sickness funds. Minimum level of financial reserves (depending on premium income). Voluntary mutual support between sickness funds of the same type.

Income dependent premiums, to a small degree services (e.g. alternative medicine). Contracts with provider of integrated care 


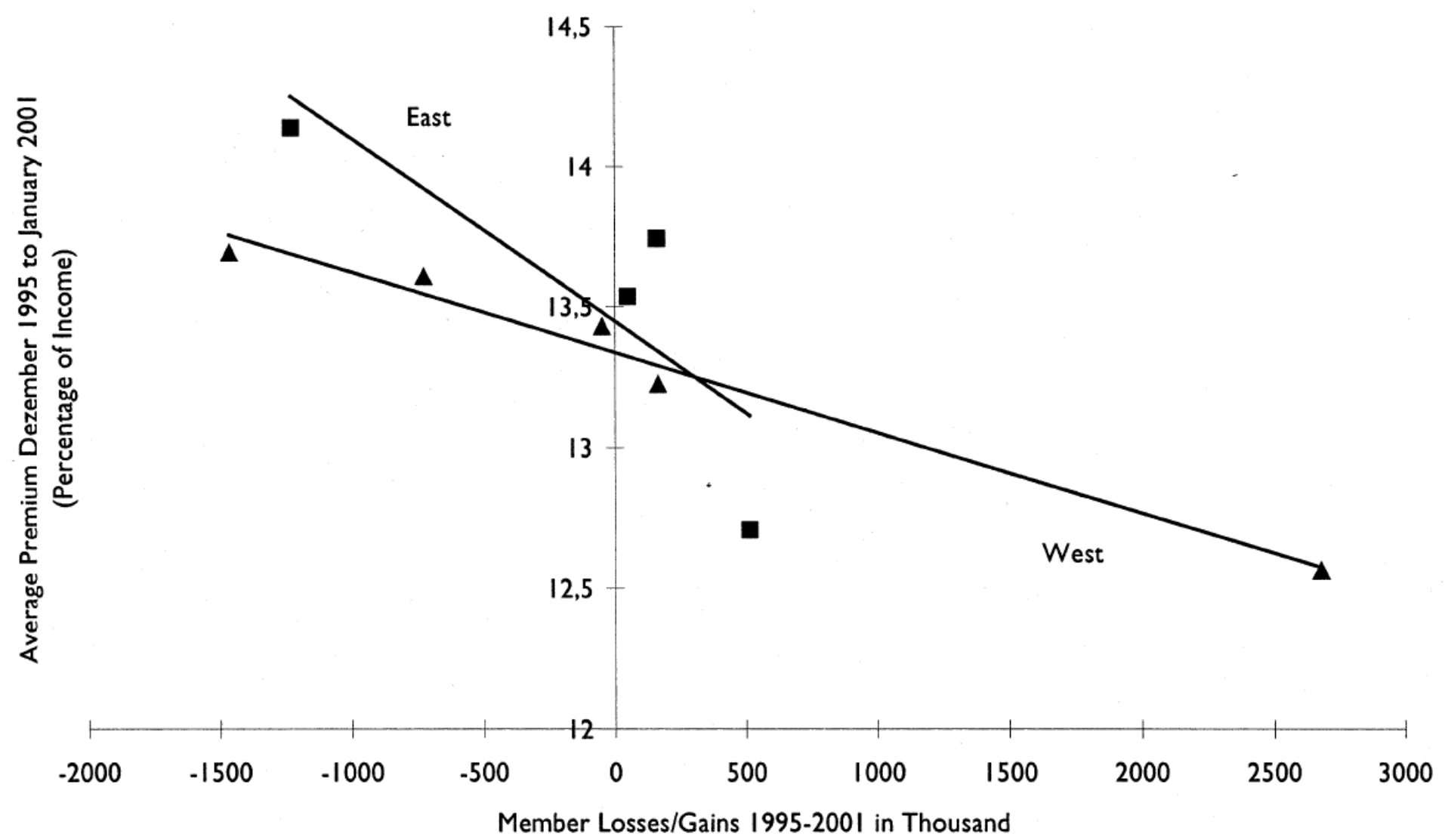

Fig. 1. Correlation between premium differences and member losses/gains by type of sickness funds 1995-2001 (West and East Germany). 
Gress, S., Groenewegen, P., Kerssens, J., Braun, B., Wasem, J.

Free choice of sickness funds in regulated competition: evidence from Germany and the Netherlands. Health Policy: 60, 2002, nr. 3, p. 235-254
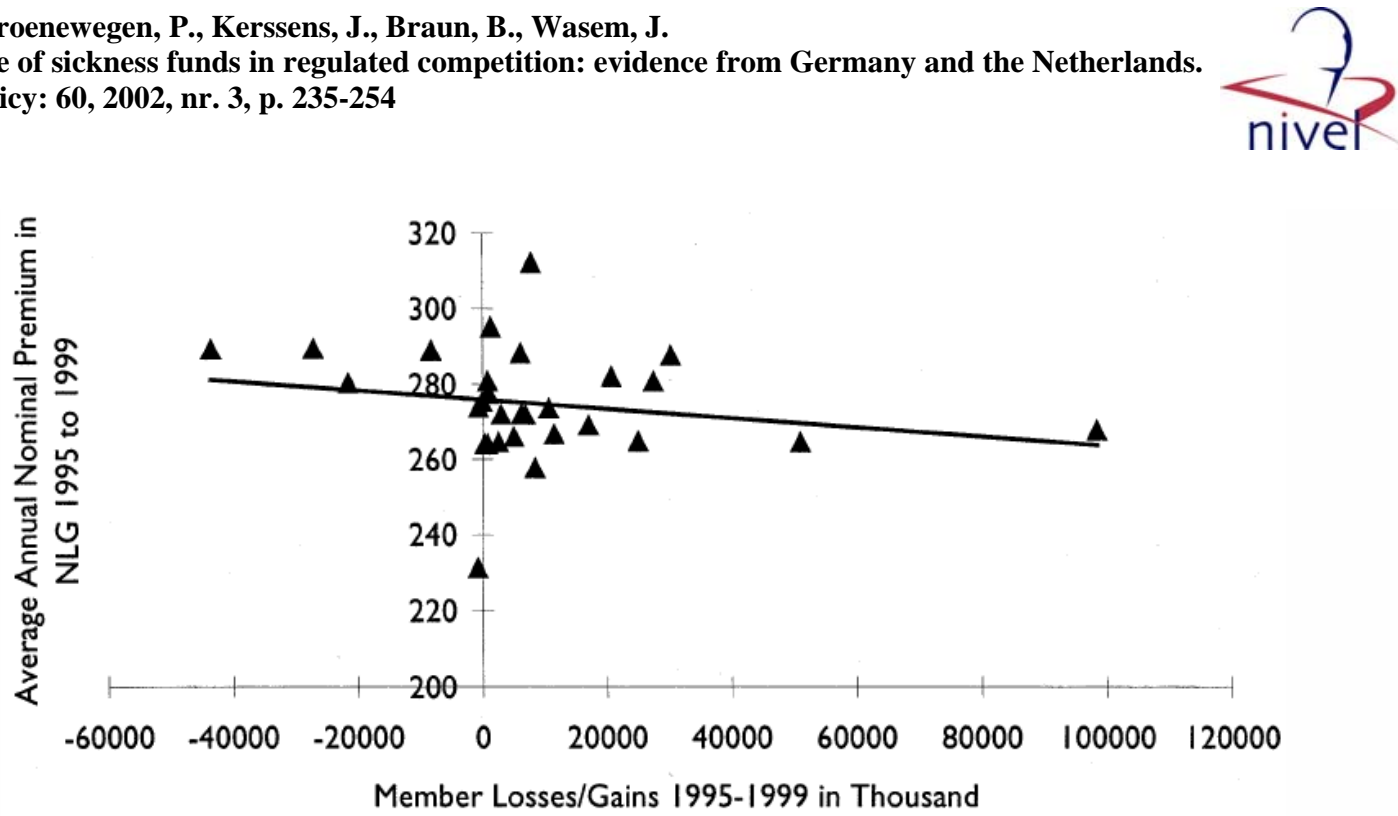

Fig. 2. Correlation between annual premium differences and member losses/gains of individual sickness funds $1995-1999$ (Netherlands).

Table 2

Percentage of insured according to their perception about differences between sickness funds on 11 aspects $(N=846)$

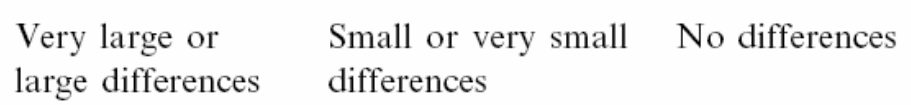

Supplementary coverage package $\quad 30$

$67 \quad 4$

Supplementary coverage premium $\quad 30$

$66-4$

Arrangements regarding complaints 26

or objections

Efforts to cut down waiting lists 25

Speed in which bills are 24

$62 \quad 13$

remunerated

Accessibility by telephone 23

Consumer orientation 22

$62-16$

Flat rate premium

Compensation for medication $\quad 15$

Basic benefit package 14

Compensation for medical $\quad 12$

$67 \quad 10$

specialists

Source Ref. [26]. 